\title{
Epidemiological Characteristics of Great Depression Diseases of Hospitalized Patients in Psychiatric Hospital "Negorci" for a Five- Year Period From 2013 to 2017
}

\author{
Biljana lliev, Dimitar Bonevski, Andromahi Naumovska
}

${ }^{1}$ Clinical Hospital Shtip, Shtip, Republic of Macedonia; ${ }^{2}$ Department of Psychiatry and Medical Psychology of Medicine, Faculty of Medicine, Ss. Cyril and Methodius University, Skopje, Republic of Macedonia

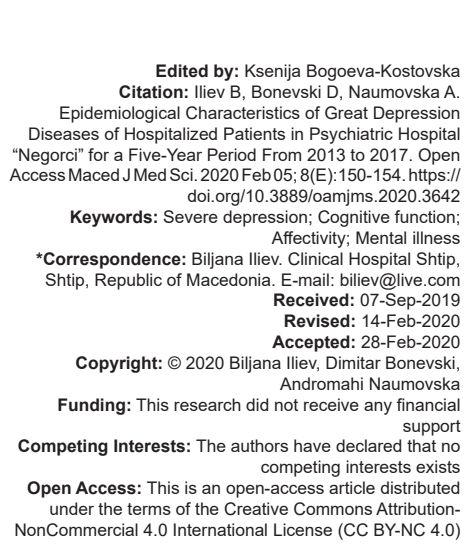

\section{Introduction}

Depressive diseases affect a wide range of mental health changes, ranging from grief and intimidation, insomnia with psychosomatic complaints, to psychotic symptoms, such as crazy ideas, hallucinations, stupor mental disorders within the severe depression, and a diagnostic entity with a chronic course [1], [2]. The World Health Organization estimates that, in most parts of the world, most of the population suffers from mental illnesses that manifest themselves with depressive phenomena at least once in their life, regardless of gender, age, demographic and sociocultural characteristics, religious affiliation, and persuasion [3].

Terminological and nosological depression is an affective disorder with primary disorder (reduction) of cognitive functions, alteration of affectivity, psychomotor retardation, and social isolation. Thinking content is depressed, accompanied by suicidal ideations or attempts to commit suicide [4].
Research performed on hospitalized patients under the diagnosis severe depression suggests that depressive disorders are among the top two leading causes of disability due to illness. The consequences of this disease and the loss of health are great. Depression ranked by the $\mathrm{WHO}$ as the biggest contributor to global incompetence $-7.5 \%$ of all ages in 2015.

Globally, it is estimated that over 300 million people suffer from depression equivalent to $4.4 \%$ of the world's population. The percentage of the global population with severe depression in 2015 is estimated at $4.4 \%$. Severe depression is more common in women $(5.1 \%)$ than men $(3.6 \%)$. Prevalence rates differ by age - over $7.5 \%$ in women aged $55-74$, and over $5.5 \%$ in men of the same age. The WHO does not have any data on the prevalence of severe depression in the Republic of North Macedonia for the period of 2005-2016 (which is also a motive for this survey) while in the neighboring countries, the data are Albania 4.8\%, Bulgaria 5.2\%, and Greece $5.7 \%$ [5]. 
Over the past few years, the results of the studies have shown that sociodemographic factors play a significant role in abnormal functional activity and are recognized as the main triggers for the pathogenesis and severity of severe depression. In Bangladesh, a study based on hospitalized patients investigating sociodemographic factors and their correlation with the severity of severe depression [6] shows that 56\% (133) are men and 44\% (106) are women. Of the married people, $56 \%$ had a tendency to develop depression compared to unmarried persons, where the percentage was $36 \%$. Residents of urban areas, $64 \%$, are more likely to suffer from depression than those in rural areas. Correlation analysis shows that age, gender, marital status, education, family income, and place of residence are related to the severity of the disease. In addition, age, marital status, and place of residence are positively correlated with the severity of severe depression, while sex, education, and family income are negatively correlated with the severity of the severe depression. It has been established that the sociodemographic factors associated with depression are low socioeconomic status, poor educational background, and death of a spouse.

In Canada, the prevalence of severe depression was found in $15.4 \%$ single mothers compared to $6.8 \%$ in married mothers [7], [8]. Many studies confirm a marked negative correlation between mental disorder and socioeconomic status in the United States and Canada (Ontario) [9], [10].

The current study shows that age, gender, education, employment status - unemployment, marital status, and place of residence are related to the severity of depression and is a challenge for research in the field of affective psychiatric disorders.

\section{Objectives}

The main goal is to determine the total number of patients with severe depression treated in the Psychiatric Hospital "Negorci" - Negorci over 5 years, retrospectively in 2013 until 2017 and determining the impact of sociodemographic variables as risk factors and predictors.

\section{Secondary goals}

1. Obtain a clear picture of the factors that lead to the development of severe depression.

2. The influence of gender, age, education, employment, marital status, and place of residence (rural or urban environment) as sociodemographic characteristics of the onset of severe depression.

\section{Materials and Methods}

\section{Population, sample, and instruments}

The study is retrospective and is performed by collecting data from the medical documentation of treated patients in the Psychiatric Hospital "Negorci" Negorci, in the period from 2013 to 2017 . Out of the total number of patients treated at the hospital (1792) over 18 years of age, a sample of 63 patients, expressed as a percentage of $3.51 \%$, is composed of patients diagnosed with ICD 10 with diagnosis - F32, severe depression, F32.2 - severe depressive episode without psychotic symptoms, and F32.3 severe depressive episode with psychotic symptoms.

Given that, the purpose of the research is to obtain a clear picture of which the sociodemographic characteristics have the biggest influence on the occurrence of major/severe depression, a short questionnaire has been created that contains items for sex, age, education, and marital status of the patients from the sample and it is filled with taking of data from the medical documentation of the patients.

The collected data are statistically processed in the SPSS program, using descriptive statistics (frequencies, percentages, graphs, etc.). The descriptive statistics show the characteristics of severe depression in the Psychiatric Hospital "Negorci" - Negorci in the examined sample. The effects of different factors on the occurrence of severe depression have been checked by cross-regulation.

\section{Inclusion criteria}

Patients with severe depression with and without psychotic elements were included in the study.

\section{Exclusion criteria}

The following criteria were excluded from the study:

- $\quad$ Bipolar affective disorder

- Depressive phases in schizophrenic patients

- $\quad$ Senile paranoid-depressive disorders.

\section{Results}

The total number of admissions to the Psychiatric Hospital "Negorci" - Negorci in the period from 2013 to 2015 is decreasing, and in 2016, it notices its peak, a data that are in negative relation with the growth of patients with severe depression in the period from 2014 to 2015 ; meanwhile, in contrast, the number of patients 
Table 1: Distribution of respondents according to gender and education variables

\begin{tabular}{|c|c|c|c|c|c|}
\hline \multirow[t]{2}{*}{ Cross tabulation } & \multicolumn{5}{|l|}{ Education } \\
\hline & No education & Elementary school & High school & University & Total \\
\hline \multicolumn{6}{|l|}{ Gender } \\
\hline \multicolumn{6}{|l|}{ Men } \\
\hline Count & 10 & 15 & 8 & 1 & 34 \\
\hline Percentage of within gender & 29.4 & 44.1 & 23.6 & 2.9 & 100 \\
\hline Percentage of within education & 66.7 & 48.4 & 53.3 & 50 & 54 \\
\hline Percentage of total & 15.9 & 23.8 & 12.7 & 1.6 & 54 \\
\hline \multicolumn{6}{|l|}{ Women } \\
\hline Count & 5 & 16 & 7 & 1 & 29 \\
\hline Percentage of within gender & 17.2 & 55.2 & 24.1 & 3.5 & 100 \\
\hline Percentage of within education & 33.3 & 51.6 & 46.7 & 50 & 46 \\
\hline Percentage of total & 7.9 & 25.4 & 11.1 & 1.6 & 46 \\
\hline \multicolumn{6}{|l|}{ Total } \\
\hline Count & 15 & 31 & 15 & 2 & 63 \\
\hline Percentage of within gender & 23.8 & 49.2 & 23.8 & 3.2 & 100 \\
\hline Percentage of within education & 100 & 100 & 100 & 100 & 100 \\
\hline Percentage of total & 23.8 & 49.3 & 23.8 & 3.2 & 100 \\
\hline
\end{tabular}

with severe depression who are treated at the hospital is growing, especially in 2015, it reaches its peak.

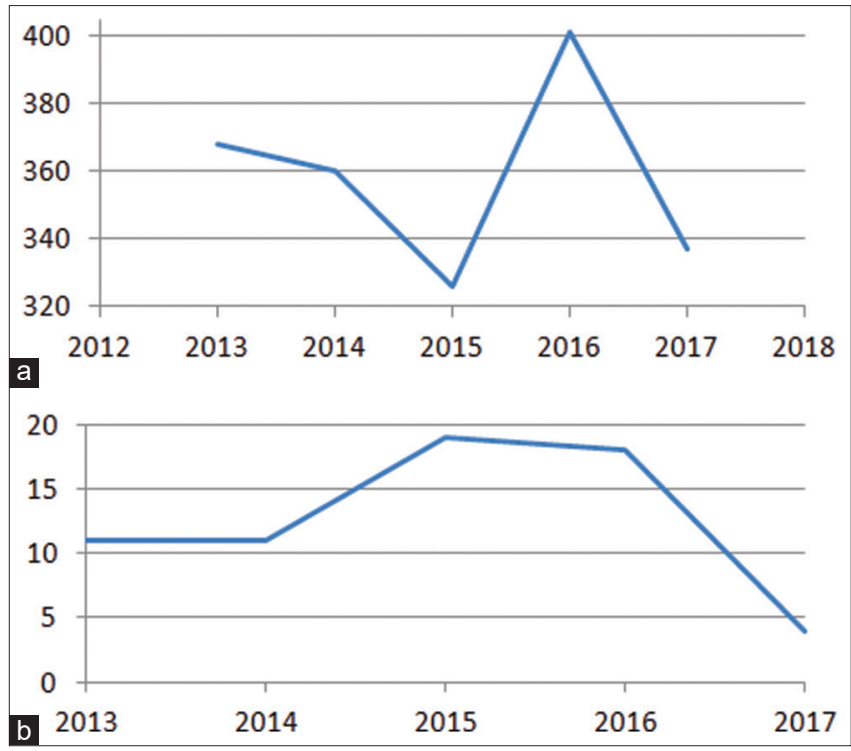

Figure 1: (a) Number of patients (treated hospitals) admitted to the hospital by years; (b) Number of patients with severe depression who are admitted to the hospital

Of the 1792 hospitalized patients, 63 are diagnosed with severe depression, expressed as a percentage of $3.51 \%$. In 2013 , of the total 368 patients admitted, $11(2.9 \%)$ are severely depressed, in 2014 , out of 360 patients, 11 (3.05\%) are severely depressed, in 2015, of the 326 admitted patients, 19 (5.8\%) are severely depressed, in 2016, of 401 hospitalized patients, 18 (4.48\%) with severe depression, and in 2017 , of a total of 337 patients, $4(1.18 \%)$ are severely depressed (Figure 1).

The sample consists of a total of 63 patients with severe depression who were hospitalized at the Psychiatric Hospital "Negorci" in the period from 2013 to 2017 . Of these, $46 \%$ are men and $54 \%$ are women, which show a greater prevalence of women with major/ severe depression in this hospital compared to men.

Regarding age in patients with major/severe depression, a range of 28-71 years old is observed, but with an increased frequency between 45 and 62 years. The average age of the respondents is 52.14 years (Figure 2).

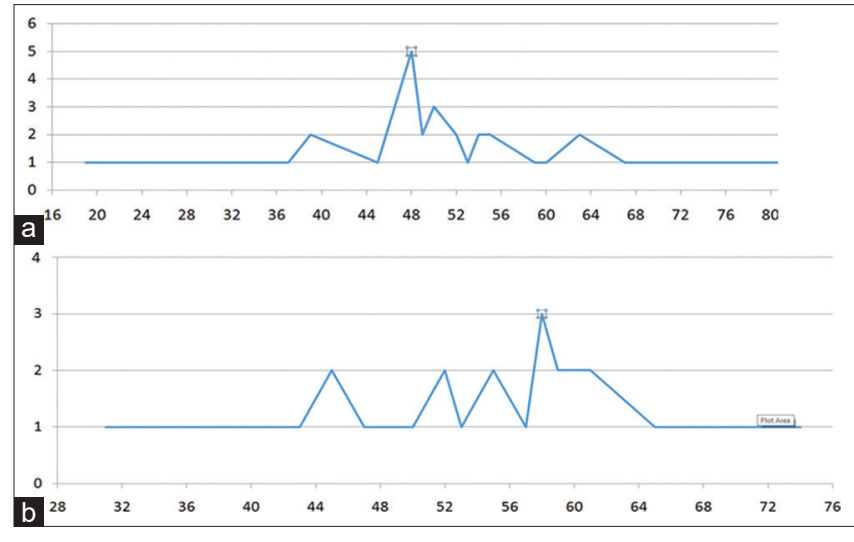

Figure 2: (a) Graphic presentation of major/severe depression in relation to the age of female patients; (b) Graphical presentation of major/severe depression in relation to the age of male patients

Most (55\%) of patients have completed primary education and at least with a university degree that is only $1(1.6 \%)$, Figure $3 a$.

Most (44\%) of patients have completed primary education and at least with higher education that is only $1(2.9 \%)$, Figure $3 b$.

The largest part (49\%) of patients has completed primary education and at least with higher education that is only $2(3.1 \%)$, Figure $3 c$.

There was no statistically significant difference between the genders in terms of completed education.

From the display of the cross-sectional variation of education and gender in Table 1, it can be noted that, to a large extent, $66.7 \%$ of men who are without education are severely depressed.

Regarding the activity of patients, only 12 of them, is $19.05 \%$, are employed, and even $80.95 \%$ are unemployed.

Most of the patients $82.54 \%$ are married, $25.4 \%$ are widowed, $11.11 \%$ are single, and only $4.76 \%$ are divorced (Figure 4).

From the display of the intersection of the variable labor relation and marital status in Table 2, it can be noted that the unemployed status significantly influences a greater prevalence of severe depression, that is, in all four marital statuses (divorced $3.2 \%$, male 


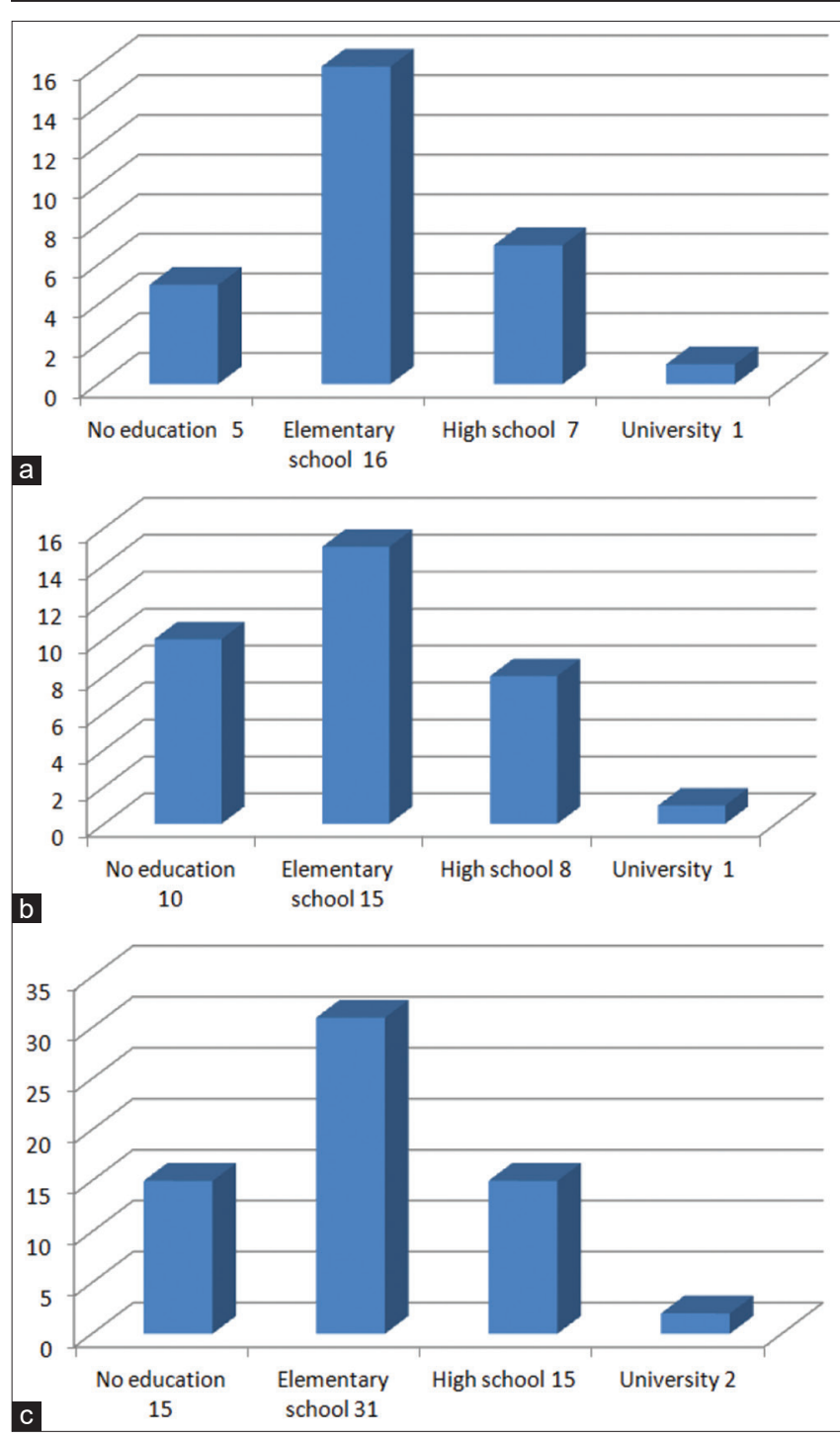

Figure 3: (a) Graphical depiction of the major depression in terms of the completed education of female patients; (b) Graphic presentation of major/severe depression in terms of completed education of male patients; (c) Graphic presentation of major/severe depression in terms of completed education of patients of both genders

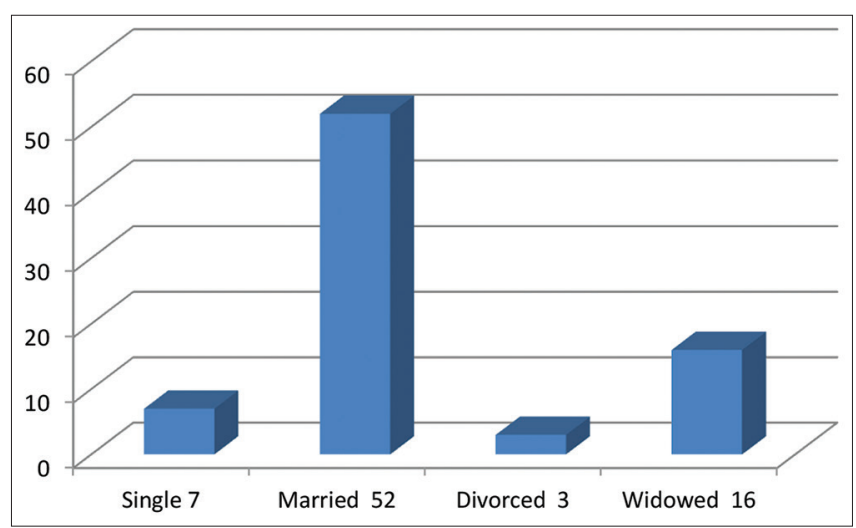

Figure 4: Graphic presentation of major/severe depression regarding the marital status of patients

$7.9 \%$, widowed $17.4 \%$, and married $50.8 \%$ ), percentage of severe depression is higher in relation to the status of an employee.
Table 2: Crossing the variables marital status and working relationship according to the place of residence there is no big difference, $57.1 \%$ live in the urban environment and $42.9 \%$ live in a rural environment

\begin{tabular}{|c|c|c|c|}
\hline \multirow[t]{2}{*}{ Cross tabulation } & \multicolumn{3}{|c|}{ Employed/Unemployed } \\
\hline & Employed & Unemployed & Total \\
\hline \multicolumn{4}{|l|}{ Marital status } \\
\hline \multicolumn{4}{|l|}{ Single } \\
\hline Count & 1 & 5 & 6 \\
\hline Percentage of within marital status & 16.7 & 83.3 & 100 \\
\hline Percentage of within employed & 7.7 & 10 & 9.5 \\
\hline Percentage of total & 1.6 & 7.9 & 9.5 \\
\hline \multicolumn{4}{|l|}{ Married } \\
\hline Count & 9 & 32 & 41 \\
\hline Percentage of within marital status & 22 & 78 & 100 \\
\hline Percentage of within employed & 69.2 & 64 & 65.1 \\
\hline Percentage of total & 14.3 & 50.8 & 65.1 \\
\hline \multicolumn{4}{|l|}{ Widowed } \\
\hline Count & 2 & 11 & 13 \\
\hline Percentage of within marital status & 15.4 & 84.6 & 100 \\
\hline Percentage of within employed & 15.4 & 22 & 20.6 \\
\hline Percentage of total & 3.2 & 17.4 & 20.6 \\
\hline \multicolumn{4}{|l|}{ Divorced } \\
\hline Count & 1 & 2 & 3 \\
\hline Percentage of within marital status & 33.3 & 66.7 & 100 \\
\hline Percentage of within employed & 7.7 & 4 & 4.8 \\
\hline Percentage of total & 1.6 & 3.2 & 4.8 \\
\hline \multicolumn{4}{|l|}{ Total } \\
\hline Count & 13 & 50 & 63 \\
\hline Percentage of within marital status & 20.6 & 79.4 & 100 \\
\hline Percentage of within employed & 100 & 100 & 100 \\
\hline Percentage of total & 20.7 & 79.3 & 100 \\
\hline
\end{tabular}

\section{Discussion}

This study was conducted to investigate the sociodemographic status of patients with severe depression who were hospitalized in Psychiatric Hospital, "Negorci" - Negorci in the period of 2013-2017. A correlation was also found between sociodemographic status and severity of the disorder. Our findings consistent with the study are comparable to similar previous studies in some other countries Germany, China, and Canada.

This study found that $46 \%$ of men and $54 \%$ of women were similar to some previous studies that reported that women were more likely to develop severe depression [12]. According to the current study, patients with severe depression were found to have an increased frequency between 45 and 62 years. The mean age of the respondents was 52.14 years. According to the level of education, the majority $(49 \%)$ of the patients have completed primary education and the least with higher education, i.e., only $2(3.1 \%)$.

The results are comparable to the previous studies reporting an association between people with educational status and depression, significantly more severe depression occurs in those with lower education [13]. Among all respondents, $80.95 \%$ are unemployed and $19.05 \%$ are employed, which is in line with a study in China which claims that the lower the socioeconomic status, the higher the rate of severe depression [13]. Out of the total number of respondents, the percentage of severe depression according to marital status is higher in those who are married $50.8 \%$, divorced $3.2 \%$, alone/unmarried $(7.9 \%)$, and widowed $17.4 \%$. This result is consistent with other previous 
studies where marriages (married people) have an increased risk of developing severe depression [14]. Residents of urban areas $57.1 \%$ are more likely to suffer from depression than those of rural areas $42.9 \%$, which are similar to other findings in other studies [15].

This study concludes that age, gender, marital status, education level, employment/unemployment status, and place of residence are associated with the severity of depression. Age, marital status, and place of residence with severe depression were positively correlated with the severity of the disease, while education and employment/unemployment status were negatively correlated with the severity of depression. This strong link between depression and sociodemographic status will play an important role in understanding and treating the disease.

Of particular interest is the fact that the number of those treated at the Psychiatric Hospital - "Negorci" - Negorci with well-developed psychiatric care and treatment is high because the time spent in the hospital setting is longer because there is no developed outpatient treatment, which would reduce hospitalization. For a more precise conclusion, the research needs to be conducted on a large number of respondents from different regional parts of the Republic of Macedonia. Despite these limitations, we hope that our study will play an important role in understanding the relationship between sociodemographic status and the severity of depression.

\section{Conclusion}

This study concludes strong link between depression and sociodemographic status will play an important role in understanding and treating the disease. This research is the beginning of the research on the representation of Severe Depression in Republic of Macedonia for which the WHO has no data for the last 10 years, and also the basis for research projects on the representation of Severe Depression in hospital conditions and further in outpatient institutions.

\section{References}

1. Islam R, Adnan R. Socio-demographic factors and their correlation with the severity of major depressive disorder: A population based study. World J Neurosci. 2017;7:193-202. https://doi.org/10.4236/wjns.2017.72014

2. World Health Organization. Depression and Other Common Menta Disorders, Global Health Estimates. Geneva: World Health Organization; 2017.

3. Shi J, Zhang Y, Liu F, Li Y, Wang J, Flint J, et al. Associations of educational attainment, occupation, social class and major depressive disorder among Han Chinese women. PLoS One. 2014;9(1):e86674. https://doi.org/10.1371/journal. pone. 0086674

PMid:24497966

4. Sadock B, Sadock VA, Ruiz P. Sadok and Sadok, Comprehensive Textbook of Psychiatry. Netherlands: Wolters Kluwer; 2012.

5. Scott KM, Wells JE, Angermeyer M, Brugha TS, Bromet E, Demyttenaere K, et al. Gender and the relationship between marital status and first onset of mood, anxiety and substance use disorders. Psychol Med. 2010;40(9):1495-505. https://doi. org/10.1017/s0033291709991942

PMid:19939327

6. Wang JL. Rural-urban differences in the prevalence of major depression and associated impairment. Soc Psychiatry Psychiatr Epidemiol. 2004;39(1):19-25.

PMid: 15022042

7. Kuehner C. Gender differences in unipolar depression: An update of epidemiological findings and possible explanations. Acta Psychiatr Scand. 2003;108(3):163-17. https://doi. org/10.1034/j.1600-0447.2003.00204.x PMid: 12890270

8. Lorant V, Deliège D, Eaton W, Robert A, Philippot P, Ansseau M Socioeconomic inequalities in depression: A meta-analysis. Am J Epidemiol. 2003;157(2):98-112. https://doi.org/10.1093/ aje/ kwf182

PMid: 12522017

9. Lennon MC, Blome J, English K. Depression among women on welfare: A review of the literature. J Am Med Womens Assoc. 2002;57(1):27-31.

PMid: 11905486

10. Eaton WW, Muntaner C, Bovasso G, Smith C. Socioeconomic status and depressive syndrome: The role of inter and intragenerational mobility government assistance, and work environment. J Health Soc Behav. 2001;42(3):277-94. https:// doi.org/10.2307/3090215

PMid:11668774 